\title{
Dietary intake and ghrelin and leptin changes after sleeve gastrectomy
}

\author{
Marek Bužga ${ }^{1}$, Vladislava Zavadilová ${ }^{1}$ Pavol Holéczy², Zdeněk Švagera ${ }^{3}$, Pavol Švorc ${ }^{1}$, Aleš Foltys ${ }^{2}$, Pavel Zonča ${ }^{2}$ \\ ${ }^{1}$ Department of Physiology and Pathophysiology, Faculty of Medicine, University of Ostrava, Ostrava, Czech Republic \\ ${ }^{2}$ Department of Surgical Studies, Faculty of Medicine, University of Ostrava, Ostrava, Czech Republic \\ ${ }^{3}$ Department of Sciences, Faculty of Medicine, University of Ostrava, Ostrava, Czech Republic
}

Videosurgery Miniinv 2014; 9 (4): 554-561

DOI: $10.5114 /$ wiitm.2014.45437

\begin{abstract}
Introduction: Surgical intervention in obesity is today the most effective treatment method in high level obesity management. Bariatric interventions not only ensure body weight reduction, but may influence dietary habits.

Aim: To assess changes in adipose hormones and dietary habits in obese patients after sleeve gastrectomy.

Material and methods: The study set comprised 37 subjects (29 females and 8 males) 24 to 68 years old with body mass index $43.0 \pm 4.9 \mathrm{~kg} / \mathrm{m}^{2}$. Pre-operative examination included baseline measurements of body composition. Dietary habits and intake frequency were monitored by a questionnaire method. Follow-up examinations were carried out in a scope identical to the pre-operative examination, 6 and 12 months after surgery, respectively.

Results: The average patient weight loss 12 months after surgery was $31.7 \mathrm{~kg}$. Excess weight loss was $55.2 \pm 20.6 \%$. Patients reported reduced appetite $(p<0.001)$, increasingly regular food intake $(p<0.001)$, intake of more meal portions per day $(p=0.003)$ and a decrease in consuming the largest portions during the afternoon and evening $(p=0.030)$. Plasma levels of fasting glucose, leptin and ghrelin significantly decreased ( $p=0.006 ; p=0.0 .043)$; in contrast, the level of adiponectin significantly increased $(p<0.001)$.

Conclusions: Sleeve gastrectomy and follow-up nutritional therapy resulted in a significant body weight reduction within 1 year after surgery. An improvement of certain dietary habits in patients was registered. At 12 months after surgery, there were no statistically significant differences in decreases in ghrelin and leptin concentrations between patients without changed appetite and those reporting decreased appetite.
\end{abstract}

Key words: bariatric surgery, laparoscopic sleeve gastrectomy, dietary habits, leptin, ghrelin, dietary intake frequency.

\section{Introduction}

Over the past two decades, obesity has become a serious global health problem. The International Association for the Study of Obesity/International Obesity Task Force, a WHO body [1], has reported that approximately 1 billion adults worldwide are overweight and another 475 million adults are obese. In countries of the Central and Eastern Europe, including the Czech Republic, the prevalence of obesity stands as a forefront issue in all epidemio- logical studies. Results of the latest large epidemiological study, conducted in the Czech Republic, reveal that $30 \%$ of Czechs are overweight and $25 \%$ suffer from obesity. It is an alarming fact that, during the last 6 years alone, the number of obese subjects has increased by $5 \%$ in the total population of 10.3 million, which makes 425,000 people [2].

There are several therapeutic approaches to obesity. In most cases, the first choice is lifestyle change focused on balanced dietary intake and physical activity. Pharmaceutical therapy, the principal aims of

\section{Address for correspondence}

Marek Bužga PhD, MSc, Department of Physiology and Pathophysiology, Faculty of Medicine, University of Ostrava, 19 Syllabova St, 70030 Ostrava, Czech Republic, phone: +42 07747615 81, e-mail: marek.buzga@osu.cz 
which are to support a change in dietary habits and prevent a decrease in basal metabolism, is another option. However, since the end of the 1990s, surgical treatment (bariatric/metabolic surgery) has proved to be the most effective obesity treatment $[3,4]$. Unlike conservative treatment, which fails in more than $80 \%$ of patients in the long term, bariatric surgery results in long-term success in more than $80 \%$ of patients [5]. It is the only treatment that produces long-term weight loss in morbidly obese patients [6].

Like all surgical procedures, bariatric surgery carries its own risks [7]. Although cure of associated co-morbidities cannot be guaranteed, more than $75 \%$ of obese patients experience complete or partial post-operative remission of most obesity-associated health conditions (e.g. type 2 diabetes, dyslipidemia, and hypertension) [8]. The long-term effectiveness of this treatment depends on patients meeting specific post-operative requirements regarding individual treatment options, attending regular check-ups, engaging in adequate physical activity with respect to general condition, participating actively and their ability to change life habits [9].

In sleeve gastrectomy, a predominantly restrictive form of bariatric surgery, a significant portion of the stomach along its minor curvature is removed to convert the stomach's shape into that of a sleeve. This reduction in volume results in an earlier sense of satiety when eating.

Post-operative weight loss is augmented by decreased production of hormones related to obesity (e.g. ghrelin) and changes in the pattern of gastric voiding. Ghrelin is produced predominantly by the cells of the gastric fundus, the majority of which is removed during this procedure. Ghrelin stimulates appetite, increases gastric motility and secretion, increases growth hormone secretion and reduces fat utilization [10-12]. Short-term studies have confirmed the safety and effectiveness of this restrictive procedure; however, limited long-term data (> 5 years) are available so far [9, 13-15]. Disadvantages of this procedure include the irreversible removal of a substantial portion of the stomach and the long-term possibility of gradual enlargement of the remaining portion of the stomach caused by excessive dietary intake [9]. Patients qualified for surgical treatment of obesity usually make different dietetic mistakes, which could affect their nutritional status and lead to metabolic disorders. Monitoring of dietary habits and their changes are essential to decrease the dietary deficiencies before and after surgery [16].

\section{Aim}

The main purpose of this study was to assess changes in dietary habits in obese patients 6 and 12 months after sleeve gastrectomy. The second aim was to compare changes in hormonal levels and dietary habits after this procedure.

\section{Material and methods}

\section{Patients}

A total of 37 subjects (29 women and 8 men) aged 24 to 68 years underwent laparoscopic sleeve gastrectomy. The study was approved by the Ethics Committee of the Faculty of Medicine, University of Ostrava, Czech Republic, in accordance with the ethical standards of the Helsinki Declaration of 1975 , as revised in 2000. The subjects were patients of the Gastroenterology Care Center, Surgical department, of the Vitkovice Hospital, Czech Republic and the Department of Surgery, University Hospital Ostrava, Czech Republic. Selection of subjects for the surgical treatment of obesity was carried out in accordance with the guidelines of the International Federation for the Surgery of Obesity and Metabolic Disorders (IFSO). The subjects had either body mass index $(B M I) \geq 40 \mathrm{~kg} / \mathrm{m}^{2}, \mathrm{BMI} \geq 35 \mathrm{~kg} / \mathrm{m}^{2}$ with associated co-morbidities, or $\mathrm{BMI}<35 \mathrm{~kg} / \mathrm{m}^{2}$ with a history of weight loss resulting from intensive therapy followed by regaining weight [17]. Patients with a history of stomach surgery, gastric and duodenal ulcers, thyroid disorders, gastrointestinal disorders associated with intestinal resorption dysfunction and hypolipidemic and anti-diabetic treatment were excluded. All operations were performed laparoscopically, with no conversion to an open procedure. Five trocars were used. After mobilization of the greater curvature the resection started $4 \mathrm{~cm}$ from the pylorus. No bougie was used. The resection was navigated by the end of short gastric vessels. Careful resection of the gastric fundus was done. At the proximal end of the resection, $1 \mathrm{~cm}$ of the gastric wall was left from the lateral border of the cardia fat pad. Early oral feeding started $4 \mathrm{~h}$ after the operation. No surgical complications were observed in this group of patients.

All patients underwent pre-operative and follow-up examinations $(3,6$, and 12 months after sur- 
gery). The assessment procedures - anthropometry, monitoring of serum concentrations of fasting glucose and relevant hormones and completion of a dietary habits questionnaire - were identical on each assessment occasion.

\section{Anthropometric assessment}

A basic anthropometric examination was carried out, including measurements of body weight, height, waist and hip circumference, and calculation of BMI. Body composition was determined by dual-energy X-ray absorptiometry (DXA, Hologic Discovery A, Waltham, USA).

\section{Biochemical assessment}

Serum concentrations of leptin, ghrelin, adiponectin, and fasting glucose were measured. Venipuncture was performed the morning after overnight fasting a week before the planned procedure and 6 and 12 months after it. Blood samples were processed for subsequent analysis within 20 min of venipuncture. Serum concentrations of leptin, adiponectin, and ghrelin were measured by the ELISA method (Biovendor-Laboratorni Medicina, Brno, Czech Republic) on a DSX instrument (DSX, Dynex Technologies, Chantilly, VA, USA). Serum concentrations of leptin, ghrelin and adiponectin were assessed in light of patients' appetites as reported in their responses to the questionnaire.

\section{Questionnaire}

Dietary habits were ascertained by a questionnaire method. The questions concerned size of appetite and daily food and beverage intake frequency. The intake frequency part of the questionnaire comprised 23 items and monitored the intake frequency of selected food and beverage groups (including vegetables, fruit, baked goods, meats, smoked meat products, and confectionery). This questionnaire contained individual portion definitions (e.g. one milk portion $=250 \mathrm{ml}$, one meat portion $=125 \mathrm{~g}$ ). The patients reported how often they consumed the defined quantities of food and beverages. Possible responses ranged from "several times a day" to "as an exception or never".

\section{Statistical analysis}

The anthropometry and body composition measurement results were evaluated by Student's paired t-test and changes in dietary habits by a $\chi^{2}$ test. Changes in dietary intake of individual food groups were compared with the Wilcoxon signed rank test. F-test based on a linear mixed model was used to compare concentrations of fasting serum glucose, adiponectin, ghrelin and leptin pre- and post-operatively. Wilcoxon's test was used to correlate changes in concentrations of investigated hormones with reported changes in each subject's appetite. The level of significance was set at $5 \%$. These statistical data were processed with the Stata v. 10 program and statistical software $R$ version 2.14.1. (R Development Core Team 2013).

\section{Results}

\section{Anthropometric variables}

The age at baseline was $43.5 \pm 10.2$ years and $\mathrm{BMI}$ $43.0 \pm 4.9 \mathrm{~kg} / \mathrm{m}^{2}$. Body fat comprised $47.3 \pm 4.7 \%$ of body weight (Table I). The following data were recorded at the 6-month postoperative follow-up: mean body weight reduction of $27.4 \mathrm{~kg}$, BMI reduction of $9.7 \mathrm{~kg} / \mathrm{m}^{2}$, body fat reduction of $17.7 \mathrm{~kg}$, lean body mass (LBM) reduction of $8.3 \mathrm{~kg}$, and waist and hip circumference reductions of $18.2 \mathrm{~cm}$ and $17.8 \mathrm{~cm}$, respectively (all $p<0.001$ ). Excess weight loss (EWL) was $48.5 \pm 15.6 \%$ and excess BMI loss (EBL) $56.4 \pm 18.7 \%$ (Table I).

The mean patient weight loss was $31.7 \mathrm{~kg} 12$ months after surgery. Body mass index was reduced by a mean of $11.1 \mathrm{~kg} / \mathrm{m}^{2}$, body fat by $21.4 \mathrm{~kg}$, and active body mass by $8.9 \mathrm{~kg}$. Waist circumference was reduced by $19.5 \mathrm{~cm}$ and hip circumference by $20.9 \mathrm{~cm}$ (all $p<0.001$ ). Excess weight loss was $55.2 \pm 20.6 \%$ and EBL $64.1 \pm 24.5 \%$ (Table I).

\section{Biochemical variables}

The surgical procedure resulted in a decrease in mean fasting glucose concentrations, ghrelin concentrations and concentrations of leptin in blood serum. On the other hand, plasma concentrations of adiponectin increased significantly (Table II).

\section{Dietary habits}

The results of dietary habits monitoring were similar for the follow-up 6 and 12 months after surgery. The patients demonstrated improvements in dietary habits up to 1 year after surgery. There were statistically significant increases in numbers of sub- 
Table I. Anthropometric parameter changes 6 and 12 months after surgery $(n=37 ; 29$ women and 8 men)

\begin{tabular}{|lccc|}
\hline Parameter & $\begin{array}{c}\text { Pre-operative } \\
\text { examination }\end{array}$ & $\begin{array}{c}6 \text { months } \\
\text { after surgery }\end{array}$ & $\begin{array}{c}12 \text { months } \\
\text { after surgery }\end{array}$ \\
\hline Age $[$ years] & $43.5 \pm 10.2$ & $44.1 \pm 10.1^{\mathrm{a}}$ & $44.7 \pm 10.2^{\mathrm{a}}$ \\
\hline Weight $[\mathrm{kg}]$ & $122.2 \pm 21.1$ & $94.8 \pm 18.0^{\mathrm{a}}$ & $90.5 \pm 18.3^{\mathrm{a}}$ \\
\hline BMI $\left[\mathrm{kg} / \mathrm{m}^{2}\right]$ & $43.0 \pm 4.9$ & $33.3 \pm 4.7^{\mathrm{a}}$ & $31.9 \pm 5.0^{\mathrm{a}}$ \\
\hline EWL $(\%)$ & - & $48.5 \pm 15.6$ & $55.2 \pm 20.6$ \\
\hline EBL $(\%)$ & - & $56.4 \pm 18.7$ & $64.1 \pm 24.5$ \\
\hline Waist circumference $[\mathrm{cm}]$ & $117.6 \pm 13.1$ & $99.4 \pm 11.9^{\mathrm{a}}$ & $98.1 \pm 13.2^{\mathrm{a}}$ \\
\hline Hip circumference $[\mathrm{cm}]$ & $134.9 \pm 13.2$ & $117.1 \pm 12.1^{\mathrm{a}}$ & $114.0 \pm 12.1^{\mathrm{a}}$ \\
\hline Fat DXA $(\%)$ & $47.3 \pm 4.7$ & $41.4 \pm 5.6^{\mathrm{a}}$ & $39.2 \pm 6.5^{\mathrm{a}}$ \\
\hline Fat DXA $[\mathrm{kg}]$ & $57.2 \pm 10.9$ & $39.5 \pm 9.7^{\mathrm{a}}$ & $35.8 \pm 9.9^{\mathrm{a}}$ \\
\hline LBM DXA $[\mathrm{kg}]$ & $63.7 \pm 12.9$ & $55.4 \pm 11.2^{\mathrm{a}}$ & $54.8 \pm 11.5^{\mathrm{a}}$ \\
\hline
\end{tabular}

${ }^{a}$ Comparison with pre-operative examination $p<0.001$, EWL - excess weight loss, EBL - excess BMI loss, LBM - lean body mass

Table II. Changes in serum levels of fasting glucose, ghrelin, leptin and adiponectin 6 and 12 months after the surgery ( $n=37 ; 29$ women and 8 men)

\begin{tabular}{|lccc|}
\hline Parameter & $\begin{array}{c}\text { Pre-operative } \\
\text { examination }\end{array}$ & $\begin{array}{c}6 \text { months } \\
\text { post-operative }\end{array}$ & $\begin{array}{c}12 \text { months } \\
\text { post-operative }\end{array}$ \\
\hline Glucose $[\mathrm{mmol} / \mathrm{l}]$ & $5.7 \pm 1.0$ & $5.3 \pm 0.7^{\mathrm{Ns}}$ & $5.1 \pm 0.8^{\mathrm{b}}$ \\
\hline Ghrelin $[\mathrm{ng} / \mathrm{l}]$ & $127.5 \pm 96.9$ & $62.6 \pm 60.9^{\mathrm{a}}$ & $87.5 \pm 59.1^{\mathrm{c}}$ \\
\hline Leptin $[\mathrm{\mu g} / \mathrm{l}]$ & $43.6 \pm 11.9$ & $24.9 \pm 16.7^{\mathrm{a}}$ & $24.3 \pm 13.3^{\mathrm{a}}$ \\
\hline Adiponectin $[\mathrm{mg} / \mathrm{l}]$ & $14.5 \pm 6.8$ & $16.9 \pm 9.1^{\mathrm{Ns}}$ & $24.8 \pm 12.0^{\mathrm{a}}$ \\
\hline
\end{tabular}

${ }^{a}$ Comparison with pre-operative examination $p<0.001$; ${ }^{b}$ Comparison with pre-operative examination $p<0.01$; ${ }^{c}$ comparison with pre-operative examination $p<0.05$; ${ }^{N S}$ comparison with pre-operative examination $p>0.05$

jects who ate regularly, ate more meals per day, ate snacks, and reported reduced appetite.

The number of subjects who consumed the largest portions in the afternoon and evening also decreased after a year, from 17 (45.9\%) to 7 (18.9\%). A majority of subjects (19, i.e. $51.4 \%)$ ate the largest portions at midday $(p=0.030)$. After 1 year, all study participants reported that they snacked regularly, as opposed to $27(73.0 \%)$ who reported snacking regularly at baseline $(p=0.018)$. The preferred snacks of $75.7 \%$ of subjects were baked goods and milk products whereas $24.3 \%$ of subjects preferred fruits and vegetables.

Fourteen patients (37.8\%) reported high appetite, 21 patients $(56.8 \%)$ had normal appetite and 2 patients (5.4\%) reported low appetite at baseline.

Two patients (5.4\%) had high appetite, 25 subjects $(67.6 \%)$ reported normal appetite and 10 patients (27.0\%) had low appetite after surgery.
A statistically significant decrease in appetite was found in the group of patients after the operation. Eighteen patients (48.6\%) reported a decrease in appetite (from high to normal or low appetite or from normal to low appetite) after surgery $(p=0.001)$. One woman $(2.7 \%)$ had an increase in appetite (from low to normal appetite) after surgery. There were no changes in appetite in 18 patients (48.6\%) after the operation.

Twelve months after sleeve gastrectomy, there were no statistically significant differences in decreases in ghrelin (Table III) and leptin concentrations between patients without changed appetite and those reporting decreased appetite $(p=0.857$ and $p=0.198$, respectively). Patients reporting decreased appetite after surgery had greater increases in hormone adiponectin blood concentrations than did patients reporting no change in appetite $(p=0.011)$. There were no statistically significant 
Table III. Changes in serum levels of ghrelin relative to changes in patient's appetite after the surgery

\begin{tabular}{|lccc|}
\hline Group of patients & \multicolumn{3}{c|}{ Ghrelin level [ng/l] } \\
\cline { 2 - 4 } & $\begin{array}{c}\text { Pre-operative } \\
\text { examination }\end{array}$ & $\begin{array}{c}6 \text { months } \\
\text { post-operative }\end{array}$ & $\begin{array}{c}12 \text { months } \\
\text { post-operative }\end{array}$ \\
\hline Patients with decrease of appetite $(n=18)$ & $131.8 \pm 94.2$ & $51.8 \pm 30.9^{\mathrm{b}}$ & $72.8 \pm 46.8^{\mathrm{NS}}$ \\
\hline Patients without change of appetite $(n=18)$ & $140.5 \pm 119.4$ & $52.4 \pm 41.9^{\mathrm{c}}$ & $96.2 \pm 63.1^{\text {NS }}$ \\
\hline Patient with increase of appetite $(n=1)$ & 93.9 & 86.2 & 173.5 \\
\hline
\end{tabular}

${ }^{a}$ Comparison with pre-operative examination $p<0.001,{ }^{b}$ Comparison with pre-operative examination $p<0.01$, comparison with pre-operative examination $p<0.05,{ }^{N S}$ comparison with pre-operative examination $p>0.05$

differences in decrease of body weight, BMI and body fat between patients with a decrease of appetite and those without a change of appetite $(p=0.306, p=0.500, p=0.276) 12$ months after surgery. The EWL values were not statistically different in patients of these two groups $(p=0.079)$.

\section{Intake frequency of selected food groups}

Within 6 months of surgery, the subjects reported statistically significant reduced intakes of fatty meat $(p=0.034)$, smoked meat products with high fat contents $(p=0.002)$, bread dumplings ( $p=0.016)$, and white flour baked goods and an increased intake of fish ( $p=0.002$ ) (Table IV). One year after surgery, the subjects reported statistically significantly reduced intakes of smoked meat products with high fat contents $(p=0.021)$ and distillates $(p=0.026)$ (Table IV). They also reported reduced intakes of rice, legumes, white flour baked goods, pastry, confectionery, and beer. However, these differences were not statistically significant.

\section{Discussion}

We have identified significant reductions in body weight and fat tissue weight within 1 year of sleeve gastrectomy. A bariatric surgical procedure is considered successful if it results in EWL of greater than $40 \%$ of preoperative body weight $[13,18,19]$. The EWL was $55.2 \pm 20.6 \% 1$ year after the procedure. The EWL values within 1 year after laparoscopic sleeve gastrectomy similar to our monitored set have also been reported by other authors [20-22].

In our study, within 1 year of sleeve gastrectomy, the amount of body fat had decreased on average by $8.1 \%$ of body weight (i.e. $21.4 \mathrm{~kg}$ ). The LBM had decreased by $8.9 \mathrm{~kg}$, waist circumference by $19.5 \mathrm{~cm}$, and hip circumference by $20.9 \mathrm{~cm}$. Weight loss, reduction in body fat and LBM reductions were more pronounced within the first 6 months after surgery. The reduction rates decreased in the second half of the monitored period. The rapid reduction within the first 6 months after surgery is a consequence of the dramatic changes in food intake and appetite typical

Table IV. Intake of selected food and beverage groups 6 and 12 months after surgery $(n=37 ; 29$ women and 8 men)

\begin{tabular}{|c|c|c|c|c|c|c|c|c|c|}
\hline \multirow{3}{*}{$\begin{array}{l}\text { Parameter } \\
\text { Fatty meats }\end{array}$} & \multicolumn{3}{|c|}{ Pre-operative examination } & \multicolumn{3}{|c|}{6 months after surgery } & \multicolumn{3}{|c|}{12 months after surgery } \\
\hline & \multirow{2}{*}{$\begin{array}{c}\text { Med } \\
6\end{array}$} & \multicolumn{2}{|c|}{$95 \% \mathrm{Cl}$} & \multirow{2}{*}{$\begin{array}{l}\text { Med } \\
7^{c}\end{array}$} & \multicolumn{2}{|c|}{$95 \% \mathrm{Cl}$} & \multirow{2}{*}{$\begin{array}{l}\text { Med } \\
7^{\mathrm{NS}}\end{array}$} & \multicolumn{2}{|c|}{$95 \% \mathrm{Cl}$} \\
\hline & & 5.0 & 7.0 & & 6.0 & 7.0 & & 6.0 & 7.0 \\
\hline $\begin{array}{l}\text { Smoked meat products } \\
\text { with a higher fat content }\end{array}$ & 5 & 4.0 & 5.0 & $6^{b}$ & 5.0 & 7.0 & $6^{c}$ & 4.2 & 7.0 \\
\hline Fish & 5 & 5.0 & 6.0 & $4^{b}$ & 4.0 & 5.0 & $5^{\mathrm{NS}}$ & 4.0 & 5.0 \\
\hline Bread dumplings & 6 & 5.8 & 7.0 & $7^{c}$ & 6.0 & 7.0 & $7^{\mathrm{NS}}$ & 6.0 & 7.0 \\
\hline White flour baked goods & 2 & 1.0 & 4.0 & $4^{b}$ & 3.8 & 7.0 & $4^{\mathrm{NS}}$ & 2.0 & 6.8 \\
\hline Distillates & 7 & 7.0 & 7.0 & $7^{\mathrm{NS}}$ & 7.0 & 7.0 & $7^{c}$ & 7.0 & 7.0 \\
\hline
\end{tabular}

${ }^{a}$ Comparison with pre-operative examination $p<0.001$, ${ }^{b}$ comparison with pre-operative examination $p<0.01$, comparison with pre-operative examination; $p<0.05$, NS comparison with pre-operative examination $p>0.05$. Med-median. Intake of food and beverage: $1-$ more than once a day; $2-$ once a day; $3-$ four to five times a week; 4 - two to three times a week; 5 - once a week; 6-at least once a month; 7 - as an exception or never 
for sleeve gastrectomy. There is a higher incidence of gastrointestinal discomfort in the initial months after surgery than later on, which also contributes to body weight reduction. Later on the patients get used to regular dietary habits and intake of smaller portions of food, and are able to identify foods they have trouble digesting. Some patients also report an increase in physical activity facilitated by their reduced body weight and improved mobility.

Restrictive bariatric procedures reduce stomach volume, which causes an earlier onset of satiety at meals, limited food intake and consequent body weight loss [9, 13]. The most pronounced effect of bariatric surgery is patients' changes in dietary habits [6]. The Snyder-Marlow study [15] documented intake of much smaller meal portions 24 months after surgery and an increase in dietary intake frequency to at least five or six times a day. Our findings are similar: increasingly regular dietary intake, increase in number of daily meals, and reduction in portion sizes.

Consultations with nutritional therapists play a key role both before and after a bariatric procedure. After surgery, the main goal is to help the patient uphold adequate energy and nutrient intake, reduce gastrointestinal discomfort, and promote and maintain weight loss [15].

Further mechanisms influencing weight loss after sleeve gastrectomy include neurohumoral changes, such as decreased concentrations of ghrelin, the hunger stimulating hormone. Ghrelin is mainly produced by the cells of the gastric fundus, which is removed by sleeve gastrectomy. Studies cite significantly reduced appetites following sleeve gastrectomy even 2 years after surgery $[15,23]$. Our study also demonstrated significantly reduced appetites in the monitored subjects within 12 months of surgery. In our study, we found a decrease in ghrelin serum concentrations. However, there was no relationship between ghrelin plasma concentrations and appetite.

Ghrelin levels were lower 6 months after the operation than 1 year after the operation. This effect was probably caused by changes in regulation of ghrelin production. The removal of the majority of gastric fundus led to a decrease of ghrelin production in a short period after the operation [10, 11]. On the other hand, ghrelin levels are correlated negatively with $\mathrm{BMI}$ and suppression of ghrelin production in obese patients has been reported [24, 25]. Furthermore, states of negative energy balance are associated with increased ghrelin levels [26]. These findings may possibly explain the increase of ghrelin levels during the second half of the 12-month period of observation.

Leptin serum concentrations also decreased. It is known that leptin concentrations correspond very closely with total body fat content of an individual. They are increased in obese individuals and reduced in slender individuals [27]. Our study identifies a significant post-operative reduction in leptin concentrations. However, we found no correlation between decreased leptin concentrations and appetite. This finding is in accordance with the fact that hyperleptinemia in obese individuals does not reduce food intake or protect against development of obesity [27, 28].

On the other hand, the concentrations of another adipocyte hormone, adiponectin, increased significantly. This increase is in accordance with the findings of Matsubara et al. [29]: they stated that plasma concentrations of adiponectin are negatively correlated with BMI, amount of body fat, insulin resistance, and atherosclerosis. Increased adiponectin concentrations are found in both slender individuals and sportspersons [30, 31]. Moreover, we found a statistically significant increase in adiponectin concentrations in persons reporting decreased appetites after sleeve gastrectomy.

The patients' nutritional goal is to consume a balanced diet with sufficient representation of all food groups. Whole grains, fruit, vegetables, milk products and their substitutes and healthy fats should be added to the diet as soon as the patient can tolerate them. Added sugars, confectionery, fruit juice concentrates, fried foods, carbonated beverages, caffeine and alcohol should be limited or excluded [32]. Our study subjects significantly improved their dietary habits in this regard both 6 and 12 months after surgery, this improvement being more pronounced 6 months postoperatively, when they reported reduced intake of fatty meat, smoked meat products with high fat content, bread dumplings and white flour baked goods, and increased intake of fish. Twelve months after surgery they reported significantly reduced intake of smoked meat products with high fat content and distillates. Additional changes, albeit not statistically significant, indicated an inclination toward healthy dietary habits. Compared with the 6-month follow-up, the subjects reported negative changes in consumption of some food groups (e.g. fish and white flour baked goods) 
at the 12-month follow-up. These findings suggest stricter adherence to nutritional guidelines in the first months after surgery. Later on, as post-operative gastrointestinal discomfort diminished, minor negative changes in the intake of certain foods took place. Changes of dietary habits also depended on the patient's cooperation with a nutrition therapist, which was more intensive especially during the first postoperative months.

Recent studies have shown that restrictive bariatric procedures lead the patients to increase their intake of highly caloric liquid foods (sweet eating) and avoid foods that are difficult to digest (e.g. raw vegetables and whole meat) [6]. Our study subjects reported a small decrease in the intake of meat and sweet foods and a small increase in intake of vegetables. These results, however, were not statistically significant and most likely represent an improvement in dietary habits.

\section{Conclusions}

Sleeve gastrectomy and follow-up nutritional therapy resulted in significant body weight reduction, particularly in body fat. We found no statistically significant correlation between decreases in ghrelin and leptin concentrations and decreases in appetite 12 months after sleeve gastrectomy. There were improvements in certain dietary habits. Monitoring of changes in dietary habits and frequency of intake of individual food groups following bariatric procedures may lead to improved care for bariatric patients. A food group intake frequency questionnaire may further simplify the work of investigators and patients, particularly when the subjects are not willing to do 24-hour dietary monitoring. This study presents findings for a relatively short (12-month) period after surgery. The study subjects are included in a prospective monitoring study of 24 months duration.

\section{Acknowledgments}

This study was supported by a grant from the Ministry of Education of the Czech Republic, allocated via the University of Ostrava under registration number SGS20/LF/2013 and SGS06/LF/2014.

\section{References}

1. WHO. Obesity and overweight. Fact sheet N 311. [Online] WHO 2011. Available from: http://www.who.int/mediacentre/factsheets/fs311/en/index.html
2. Matoulek M, Svacina S, Lajka J. The incidence of obesity and its complications in the Czech Republic. Vnitr Lek 2010; 56: 1019-27.

3. Dadan J, Iwacewicz P, Hady HR. New approaches in bariatric surgery. Videosurgery Miniinv 2008; 3: 66-70.

4. Stanowski E, Pasnik K. Bariatric surgery - the current state of knowledge [Polish]. Videosurgery Miniinv 2008; 3: 71-86.

5. Fried M, Ribaric G, Buchwald JN, et al. Metabolic surgery for the treatment of type 2 diabetes in patients with $\mathrm{BMI}<35 \mathrm{~kg} /$ m2: an integrative review of early studies. Obes Surg 2010; 20: 776-90.

6. Olbers T, Björkman S, Lindroos A, et al. Body composition, dietary intake, and energy expenditure after laparoscopic Rouxen-Y gastric bypass and laparoscopic vertical banded gastroplasty. Ann Surg 2006; 244: 715-22.

7. Buzink S, Soltes M, Radonak J, et al. Laparoscopic surgical skills programme: preliminary evaluation of grade I level 1 courses by trainees. Videosurgery Miniinv 2012; 7: 188-92.

8. Wylezoł M, Paśnik K, Dąbrowiecki S, et al. Polskie rekomendacje w zakresie chirurgii bariatrycznej [Polish]. Videosurgery Miniinv 2009; 4: S31-4.

9. Fried M. Obesity surgery. In: Basics of clinical obesitology. Hainer V (eds). Grada, Prague 2011; 325-40.

10. Langer FB, Reza Hoda MA, Bohdjalian A, et al. Sleeve gastrectomy and gastric banding: effects on plasma ghrelin levels. Obes Surg 2005; 15: 1024-9.

11. Karamanakos SN, Vagenas K, Kalfarentzos F, Alexandrides TK. Weight loss, appetite suppression, and changes in fasting and postprandial ghrelin and peptide-YY levels after RouX-en-Y gastric bypass and sleeve gastrectomy: a prospective, double blind study. Ann Surg 2008; 247: 401-7.

12. Paspala I, Katsiki N, Kapoukranidou D, et al. The role of psychobiological and neuroendocrine mechanisms in appetite regulation and obesity. Open Cardiovasc Med J 2012; 6: 147-55.

13. Manchester S, Roye D. Bariatric surgery: an overview for dietetics professionals. Nutrition Today 2011; 46: 264-73.

14. Karmali S, Schauer P, Birch D, et al. Laparoscopic sleeve gastrectomy: an innovative new tool in the battle against the obesity epidemic in Canada. Can J Surg 2010; 53: 126-32.

15. Snyder-Marlow G, Taylor D, Lenhard J. Nutrition care for patients undergoing laparoscopic sleeve gastrectomy for weight loss. J Am Diet Assoc 2010; 110: 600-7.

16. Jastrzębska-Mierzyńska M, Ostrowska L, Razak Hady H, Dadan J. Assessment of dietary habits, nutritional status and blood biochemical parameters in patients prepared for bariatric surgery: a preliminary study. Videosurgery Miininv 2012; 7: 156-65.

17. Fried M, Hainer V, Basdevant A, et al. Interdisciplinary European guidelines on surgery of severe obesity. Obes Facts 2008; 1: 52-9.

18. de Aquino LA, Pereira SE, de Souza Silva J, et al. Bariatric surgery: impact on body composition after Roux-en-Y gastric bypass. Obes Surg 2012; 22: 195-200.

19. Deitel M, Gawdat K, Melissas J. Reporting weight loss 2007. Obes Surg 2007; 17: 565-8.

20. Hady RH, Dadan J, Luba M. The influence of laparoscopic sleeve gastrectomy on metabolic syndrome parameters in obese patients in own material. Obes Surg 2012; 22: 13-22. 
21. Sánchez-Santos R, Masdevall C, Baltasar A, et al. Short- and mid-term outcomes of sleeve gastrectomy for morbid obesity: the experience of the Spanish National Registry. Obes Surg 2009; 19: 1203-10.

22. Paluszkiewicz R, Kalinowski P, Wróblewski T, et al. Prospective randomized clinical trial of laparoscopic sleeve gastrectomy versus open Roux-en-Y gastric bypass for the management of patients with morbid obesity. Videosurgery Miniinv 2012; 7: 225-32.

23. Iannelli A, Dainese R, Piche T, et al. Laparoscopic sleeve gastrectomy for morbid obesity. World J Gastroenterol 2008; 14: 821-7.

24. Buss J, Havel PJ, Epel E, et al. Associations of ghrelin with eating behaviors, stress, metabolic factors, and telomere length among overweight and obese women: preliminary evidence of attenuated ghrelin effects in obesity? Appetite 2014; 76: 84-94.

25. le Roux CW, Patterson M, Vincent RP, et al. Postprandial plasma ghrelin is suppressed proportional to meal calorie content in normal-weight but not obese subjects. J Clin Endocrinol Metab 2005; 90: 1068-71.

26. Meier U, Gressner AM. Endocrine regulation of energy metabolism: review of pathobiochemical and clinical chemical aspects of leptin, ghrelin, adiponectin, and resistin. Clin Chem 2004; 50 : 1511-25.

27. Friedmann JM. The function of leptin in nutrition, weight and physiology. Nutr Rev 2002; 60: S1-14.

28. Morris LD, Rui L. Recent advances in understanding leptin signaling and leptin resistance. Am J Physiol Endocrinol Metab 2009; 297: E1247-59.

29. Matsubara M, Maruoka S, Katayose S. Inverse relationship between plasma adiponectin and leptin concentrations in normal-weight and obese women. Eur J Endocrinol 2002; 147: 173-80.

30. Delporte ML, Funahashi T, Takahashi M, et al. Pre- and post-translational negative effect of beta-adrenoceptor agonists on adiponectin secretion: in vitro and in vivo studies. Biochem J 2002; 367: 677-85.

31. Kasalicky M, Doležel R, Vernerova E, Haluzik. Laparoscopic sleeve gastrectomy without over-sewing of the staple line is effective and safe. Videosurgery Miniinv 2014; 9: 46-52.

32. Allied Health Sciences Section Ad Hoc Nutrition Committee, Aills LK, Blankenship J, Buffinton C, et al. ASMBS allied health nutritional guidelines for the surgical weight loss patient. Surg Obes Relat Dis 2008; 4: S73-108.

Received: 24.03.2014, accepted: 15.08.2014. 